\title{
Incorporate Cross-Course Knowledge Integration into Computing Education
}

\author{
Shamima Mithun, Xiao Luo \\ Computer and Information Technology Department \\ School of Engineering and Technology \\ IUPUI, Indiana, USA \\ smithun@iupui.edu, luo25@iupui.edu
}

\begin{abstract}
This research to practice full paper describes our cross-course knowledge integration approach, which uses a project-based learning environment. The structure and instructional pedagogies of some of our data management concentration courses in our department have not changed in a long time. Most of our data management courses cover theoretical knowledge without showing their practical applications. As a result, students don't find those courses interesting enough. In addition, none of our data management courses require cross-course interactions, which is the current instructional pedagogical direction. With the goal of addressing these issues and improving student learning, faculty employed a cross-course knowledge integration model to teach the advanced database design course CIT 44400. We redesigned this advanced database course as part of our data management curriculum enhancement also to align with the trends of the IT industry and to enable students to correlate knowledge learned in various courses. In this redesign process, we integrated a project that aligns with industrial projects in this higher-level course curriculum, so that students can integrate and apply theoretical knowledge gained in lower-level courses through participating in a project-based learning approach, using current technology of the field. Evaluation results show crosscourse knowledge integration-based pedagogy gives students comprehensive knowledge that improves students' performance and helps them link and apply knowledge learned in various courses.
\end{abstract}

Index Terms-cross-course knowledge integration, projectbased learning

\section{INTRODUCTION}

This paper presents the need for incorporating cross-course knowledge integration components into Engineering and Computing education. The course curriculum in the data management field should demand high levels of integration. Currently, the teaching of traditional database theory and application generally emphasizes database theory [1]. The theoretical concepts are abstract and logical. Students can lose interest in these studies if not shown the practical application of data management technologies in real cases. Integrating databases into several different application areas will improve students' understanding of database technologies comprehensively [1], [2]. For example, integrating database design and implementation courses with data extraction, processing, and integration courses will give students the big picture of the full life cycle of data management and analytics. The National Research Council's report also recommends that "More investigations are needed of teaching and learning across multiple courses in a discipline" and states that "cross-sectional studies of multiple courses within a discipline, or of all courses in a major, would enhance the understanding of how people learn the concepts, practices, and ways of thinking of science and engineering and of the nature and development of expertise in a discipline" [3]. In this research, our CIT 44400 course, ApplicationOriented Advanced Database Design, is redesigned to include cross-course interaction components through a project-based learning environment.

We did not update our data management concentration course curriculum for several years. A few courses had content overlap and did not cover current technologies. In our field, technologies are constantly evolving. For studnets to be competitive in the field, our courses should teach the latest technologies. In addition, many of our current datamanagement concentration courses teach theoretical concepts, and students lose interest in this study if not shown the practical application of data-management technologies in reallife problems, just as noted by Wang and Chen [1]. Moreover, none of our data-management courses require cross-course interactions. As a result, students also found that a few of our courses were not challenging. To address these issues, we targeted to modify our data management curriculum to teach theorical knowledge which is foundation for learning in the lower-level courses and teach applied knowledge in the higher-level courses that require to utilize theorical knowledge from lower-level courses. In this data management curriculum enhancement work, we updated three of our upper-level data management courses to reduce content overlap among courses, to cover current data management technologies, and to introduce cross-course knowledge integration. In this paper, we mostly discuss cross-course knowledge integration, which is implemented in our CIT 44400 course.

We redesigned CIT 44400-a course in our institution's data-management concentration curriculum to better align with the needs and the current trends of the IT industry and to incorporate cross-course knowledge integration. The new CIT 44400 requires students to integrate and apply theoretical knowledge from lower-level courses in their program by participating in a real-world project. In this course, students are also required to work through the full life cycle of a project, which gives them comprehensive knowledge. We used a project-based learning approach to design this course.

This is the author's manuscript of the article published in final edited form as: 
Research shows project-based learning aids students' development in technological, social, and core curriculum content [4]. This curriculum enhancement helps students link and integrate knowledge gained through multiple courses and creates an opportunity for students to apply cutting-edge technologies to real problems by working on projects.

To evaluate the newly redesigned CIT 44400 curriculum, instructional units were iteratively evaluated with various assessment items. Students' performance on the midterm examination in the new CIT 44400 course in Fall 2018 improved by $12 \%$, compared to that of the old CIT 44400 in Fall 2017. Students' project performance in the new CIT 44400 demonstrated that students successfully applied and integrated cross-course knowledge. Survey results show that $92 \%$ of students are happy with the course structure, and $87 \%$ of students think the project-based learning helps them apply concepts from lower-level courses.

\section{RELATED WORK}

In STEM education, many studies have focused on pedagogical methodologies at the level of a single course, for example, in class peer discussion to enhance understanding [5], flipped (inverted) classroom instruction [6], Problem-BasedLearning (PBL) classroom instruction [7], and research-based instruction [7]. Integrated education in STEM has had less of a presence in undergraduate education [8]. The literature suggests that integrated instruction enables students to see areas of knowledge as connected, rather than as individual, isolated subjects [9]. Some STEM integration focuses on integration of two or more concepts from different STEM disciplines into one course [10], [11]. Whiteacre et al. [11] explored an integrated freshman engineering curriculum for pre-calculus students at Texas A\&M University in 1996. This curriculum showed integration of material across the freshman classes. Some tightly integrated learning pedagogy to connect concepts into one curriculum might be a better fit for the lower-level undergraduate courses. Most upperlevel undergraduate courses are discipline or sub-discipline specific, designed to prepare students to be experts in their specific discipline. Laboy-Rush presented the advantages of project-based STEM integration [12], which is very related to our approach. Nwokeji and Frezza [13] implemented a crosscourse project-based learning in the requirement engineering by pairing students from two courses to work on projects based on the software requirements of the stakeholders. They concluded that the students had good experiences in this type of cross-course project setting, although there were a few challenge during the practicing of this setting. This research involved students from two different courses which is different from our approach. Debs and Zimpfer [14] also introduced cross-course team assignment to construction management engineering students. Similarly to [13], this research was focused on two courses and had students of two courses working on the collaborative assignment. Their results showed students liked to work in groups towards the assignment. However, they discovered that the students lacked understanding of the implications of the problem prior to developing solutions.

Our approach is different from the previous research that we provided a project-based learning experience for students to integrate the knowledge learned from multiple sophomore and junior courses.

The field of databases and data management is constantly evolving. The era of big data has motivated new paradigms in the development of data management strategies and systems. Learning theoretical concepts from different courses causes students to lose interest, without knowing the practical application of data-management technologies in real-world scenarios. Integrating the databases to a number of different application areas will improve students' understanding of database management technologies comprehensively [1], [15]. This study is the first to investigate integrated education at an upper-level data management undergraduate course. Students are encouraged to integrate knowledge they've learned in the lower-level courses by implementing a real-world data management project.

\section{CROSS-COURSE KNOWLEDGE INTEGRATION}

The objective of this research is to investigate project-based knowledge integration of multiple courses in the undergraduate curriculum. Similar to the undergraduate curriculum design of other institutions, the curriculum design of data management concentration of our department follows the rules that the sophomore (200-level) and junior (300-level) courses provide students fundamental knowledge of different areas, whereas the senior courses provide student more advanced knowledge. Often the design of these courses focuses on the topics of the course, the dedicated course outcomes, and the corresponding pre-requisites. The connections between the courses are less emphasized. Students do not have big pictures of the domain, and do not have enough opportunities to connect the knowledge through hand-on experiences. In this research, we propose to design our curriculum to have the course connected and have one dedicated senior course to provide students opportunity to integrate the fundamental knowledge through project-based learning. The Figure 1 demonstrates a framework we proposed to guide how the connections between courses should be addressed and how a senior course can be designed for knowledge integration. In this framework, the driver is real-world project. Basically, the design of the senior course should be driven by the real-world project, then the knowledge and technique skill requirements need to be identified by analyzing the real-world project. The instructors then work together to identify the courses that prepare students with the knowledge and technique skill based on the course outcomes. Then, curriculum and course redesign can be done according to identified courses. Finally, a project-based senior course can be designed to integrate the knowledge and skills that need to accomplish the real-world project. This framework can be generalized to the STEM area when the need of knowledge integration and real-world project experience are critical to students. 


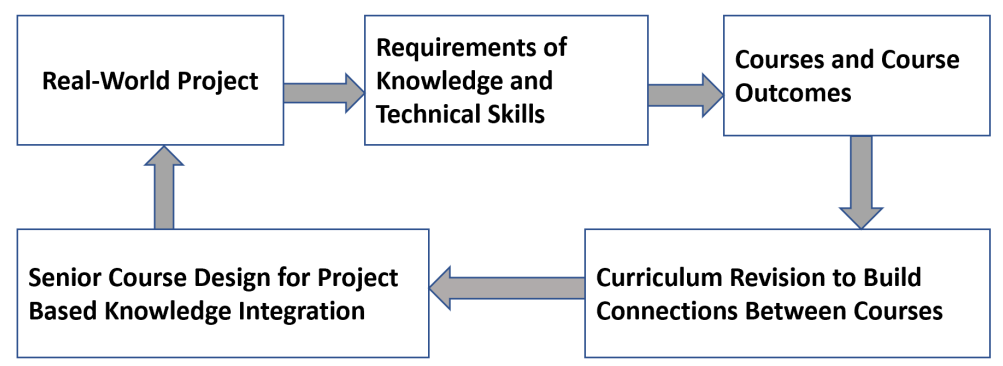

Fig. 1. Framework for Curriculum and Course Design for Knowledge Integration

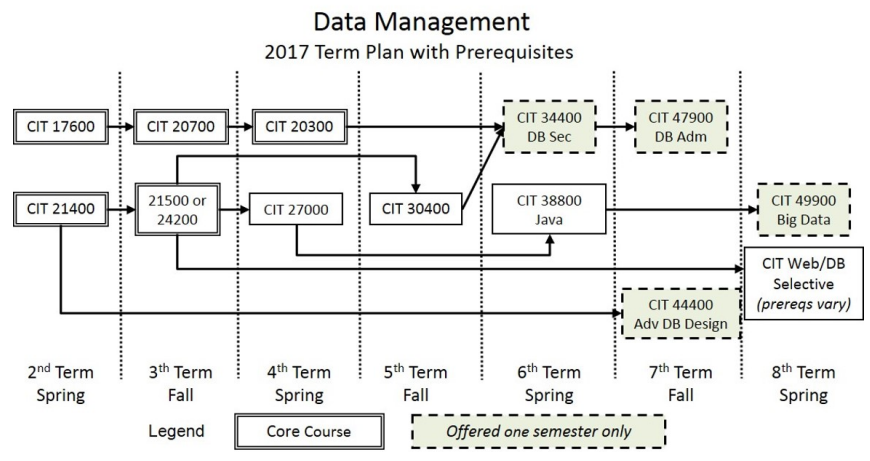

Fig. 2. Old Plan of Study

By applying this framework, specifically, we revised our data management concentration's plan of study and redesigned our CIT 44400 course.

\section{A. Data Management Curriculum Redesign}

In this project, we enhanced our CIT data management curriculum to reduce content overlap among courses, to cover current data management technologies, and to introduce crosscourse knowledge integration. As part of this enhancement, we redesigned our CIT 44400 course to mostly incorporate crosscourse knowledge integration.

The course CIT 44400 is required to be taken by all data management concentration students. Figure 2 shows the existing plan of study for the CIT data management concentration. In our curriculum, course number starting with 100s (e.g. CIT 14000) are usually recommended to take in students' freshman year; 200-level courses (e.g. CIT 21400) are recommended to take in students' sophomore year; 300-level courses are for junior year; and 400-level courses are recommend for senior year. The current plan of study shows that CIT 44400 has a single prerequisite. It also shows that 300-level and 400level courses have very minimal interaction. To address these issues, we updated the plan of study for the data management concentration. We also aligned the learning outcomes of 300level and 400-level data-management courses to minimize the content overlap among courses and to ensure lower-level courses cover foundation for the higher-level courses.

Figure 3 shows the updated plan of study for the datamanagement concentration. It demonstrates that the new CIT

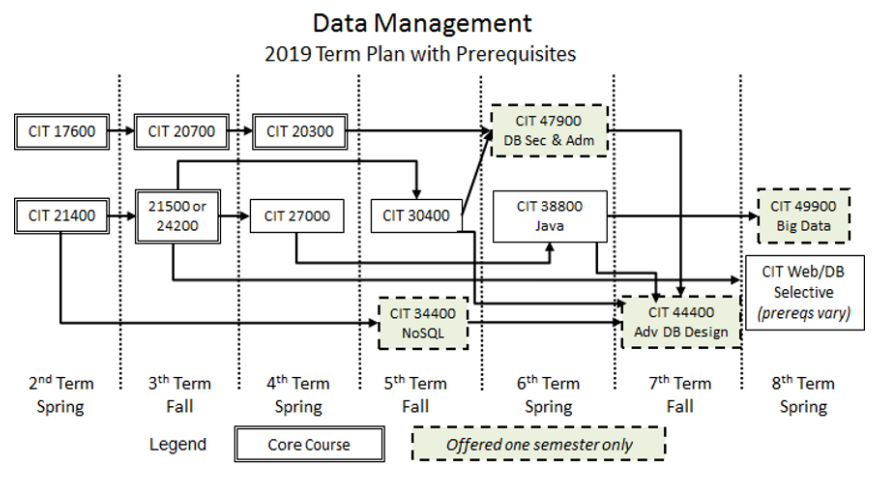

Fig. 3. Updated Plan of Study

44400 course requires students to integrate and apply knowledge from CIT 30400, CIT 34400, CIT 38800, CIT 47900, and lower-level programming and data management courses. Table I shows the learning outcomes of the above mentioned courses.

\section{B. CIT 44400 Course Redesign}

CIT 44400 was developed seven years ago. The structure and instructional pedagogies of CIT 44400 had not changed since then. Best practices and technologies in the Information Technology domain are rapidly evolving. It was time to revise this course, so it aligns with the most cutting-edge technologies and best practices in the industry.

We redesigned CIT 44400 to an application-oriented, project-based course where students need to apply knowledge from lower-level database and programming courses, such as CIT 30400, Database Programming, CIT 38800, Java Programming, and other courses by participating in a scaled down real-world project. In this new course, students are required to work with the full life cycle of a project (requirements analysis, design, implementation, and testing), which gives them comprehensive knowledge. Figure 4 shows the life cycle of the CIT 44400 course project. It also shows tasks associated in each phase, and knowledge integration incorporated from lower-level courses. This course project also requires students to deal with vast amounts of real-life data. Students had technology flexibility in term of which programming or data management languages they utilize for 
TABLE I

Learning Outcomes of Data Management Courses Involved in the Knowledge Integration

\begin{tabular}{|c|c|}
\hline Courses & Learning Outcomes \\
\hline CIT 21400 Introduction to Data Management & $\begin{array}{l}\text { - Understand basic data management concepts } \\
\text { - Understand the structure and methods of the relational data model } \\
\text { - Create and manipulate relational databases using QBE and SQL } \\
\text { - Model logical data requirements using entity-oriented techniques } \\
\text { - Transform a logical data model into a relational database structure } \\
\text { - Apply normalization techniques to a database } \\
\text { - Understand the functions of a DBMS and database administration }\end{array}$ \\
\hline CIT 30400 DB Programming & $\begin{array}{l}\text { - Write complex SQL queries and use advanced DML and DDL statements } \\
\text { - Use a variety of variable types to handle data in a block } \\
\text { - Conditionally process statements using control structures } \\
\text { - Manage errors with exception handlers } \\
\text { - Create and use procedures and functions and bundle programs units with packages } \\
\text { - Develop database triggers and perform basic statement tuning }\end{array}$ \\
\hline CIT 34400 NoSQL Design & $\begin{array}{l}\text { - Install, configure, and administer a NoSQL database } \\
\text { - Create, configure, and manage database indexes, collections, documents and users } \\
\text { - Administer database recovery and backup } \\
\text { - Create and manipulate NoSQL database objects using scripts } \\
\text { - Model logical data requirements using entity-oriented techniques } \\
\text { - Understand basic database security with NoSQL database }\end{array}$ \\
\hline CIT 38800 JAVA II & $\begin{array}{l}\text { - Review and expand introductory Java topics } \\
\text { - Explain and implement the three-tier design approach to OO development } \\
\text { - Use and create advanced controls and classes } \\
\text { - Apply problem-solving techniques in designing computer applications } \\
\text { - Implement object-oriented software solutions using inheritance, interfaces and composition } \\
\text { - Find relevant class information using the Java API specification } \\
\text { - Implement client/server applications } \\
\text { - Create programs with graphical user interfaces }\end{array}$ \\
\hline CIT 47900 DB Implementation and Administration & $\begin{array}{l}\text { - Install, configure, and administer a database } \\
\text { - Create, configure, and manage tablespaces, control files, indexes, tables, and users } \\
\text { - Administer database recovery, backup, and concurrency controls }\end{array}$ \\
\hline
\end{tabular}

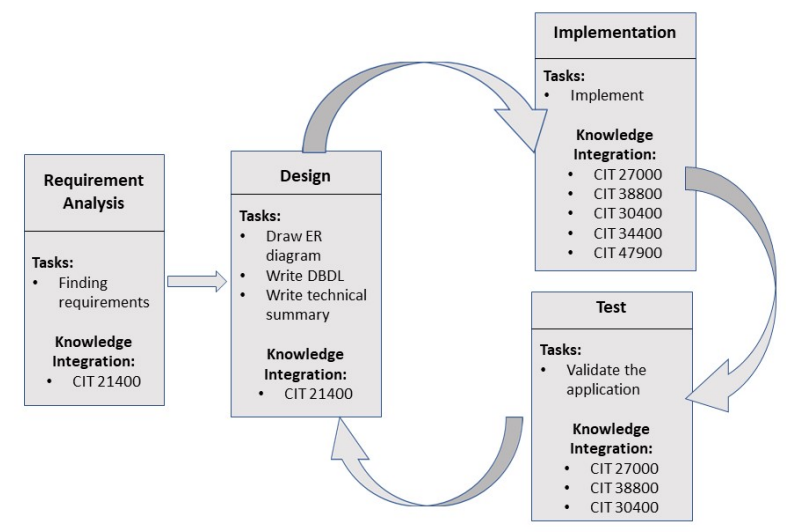

Fig. 4. Life Cycle of CIT 44400 Course Project

application development.

Course Project Description: The newly designed CIT 44400 was taught for the first time in Fall 2018. In Fall 2018, in the CIT 44400 course project, students need to develop an application that analyzes customer reviews on hotels, calculates 
hotel ratings, and presents that information using a friendly and interactive user interface. In the following subsections the Fall 2018 CIT 44400 project description is provided.

1) Overview: With the rapid growth of the Social Web, a large number of informal opinionated texts are available covering a wide range of topics. However, many people are overwhelmed with this vast amount of information and need help sifting through all of the data. Automated tools for automatically analyzing these opinions become necessary to help individuals, organizations, and governments in making timely decisions. To address this need, in this course project students develop an application that analyzes customer reviews regarding hotels. In this application, users will be provided with an overall rating of a hotel as well as ratings of a hotel's specific features, such as service, cleanliness, or location. To validate this approach, students built a query interface to analyze hotel reviews for a given user query. One of the objectives of this course project was to integrate a database to a real-life application, such as hotel review rating analyze system. Another objective was to explore the full life cycle of a real-world problem (shown in Figure 4). As shown in Figure 4 , for the hotel review rating process domain, students needed to perform a requirement analysis, design, implement, and test the application. Figure 4 also shows that students needed to build this application in an iterative manner. To implement this project, students need to apply knowledge they learned in their 200-, 300-, and 400-level courses. Figure 5 shows architecture of this hotel review rating process application and knowledge integration information from lower-level courses. This is the architecture students design, implement, and test to fulfill project requirements. In this course project, students also learned new data processing (e.g., tokenization, parsing) and interface design technologies (e.g., JavaFX, SceneBuilder) and applied those. The following sections will provide details on each module shown in Figure 5.

2) Input Data Processing: On the hotel domain, a large number of customer reviews was provided from open source datasets named "opinRank Dataset" [16]. The dataset contains over 200,000 reviews on over 2000 different hotels. This datasets contain lots of noises and irrelevant information. This textual data needed to be processed and stored in a database to allow users to query a topic in real time. Identifying the best way of processing this data was one of the challenging tasks associated with this project and was a great learning experience for students. To complete these tasks, students utilized knowledge they learned in CIT 21400, CIT 27000, CIT 38800, and newly learned knowledge in CIT 44400.

3) Hotel Rating Feature Selection: In this application, users could perform a query for pre-stored hotel information in the database. To rate each hotel, students needed to use a predefined set of features such as cleanliness, service, price, location, and others. Students were required to analyze the input dataset to find the right set of features. Students accomplished this task using knowledge learned in CIT 30400 and CIT 34400.

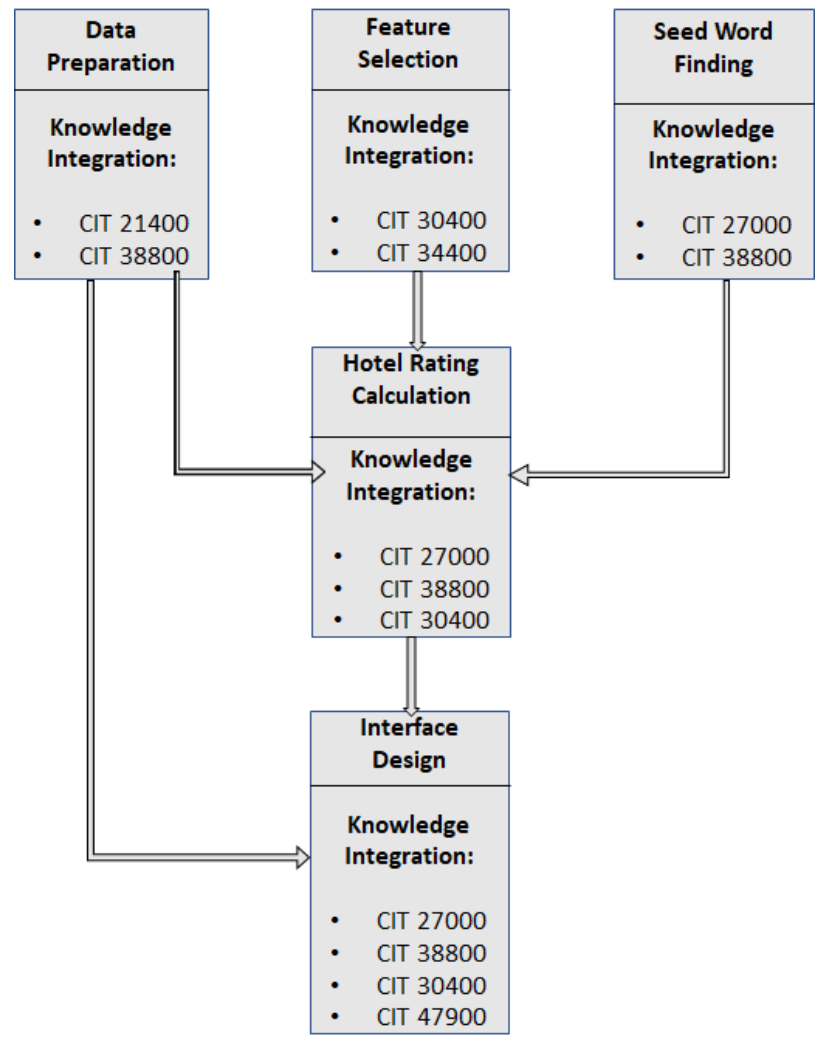

Fig. 5. Hotel Rating Application Architecture

TABLE II

SAMPLE SEed Words For Different CATEgories

\begin{tabular}{|c||c|}
\hline Features & Seed Words \\
\hline \hline Cleanliness & clean place, clean, very clean, dirty place \\
\hline Service & excellent staff, poor service \\
\hline
\end{tabular}

4) Hotel Rating Process: In this phase, students were required to formulate an evaluation method of rating a hotel with its associated features (e.g., service, price, location, and others). Customers express their opinions (e.g., very clean, expensive) and emotions regarding the hotel in their reviews. Students used these opinionated words or phrases (e.g., very clean, expensive) in their approaches to rate a hotel. Students analyzed the input dataset or devised an approach to find seed words for each feature, as shown in Table II. Students also noted if seed words are positive or negative, assigning weight for seed words. For example, they assigned positive one for a positive seed word or phrase (in Table II, shown in black) and negative one for a negative word or phrase (in Table II, shown in red). Then they used these weight values to calculate a hotel's overall rating, as well as the rating for a specific feature. Different students used different approaches for finding seed words and rating calculations utilizing previously learned knowledge in CIT 30400, CIT 34400 , CIT 38800, and newly learned knowledge in CIT 44400 . 


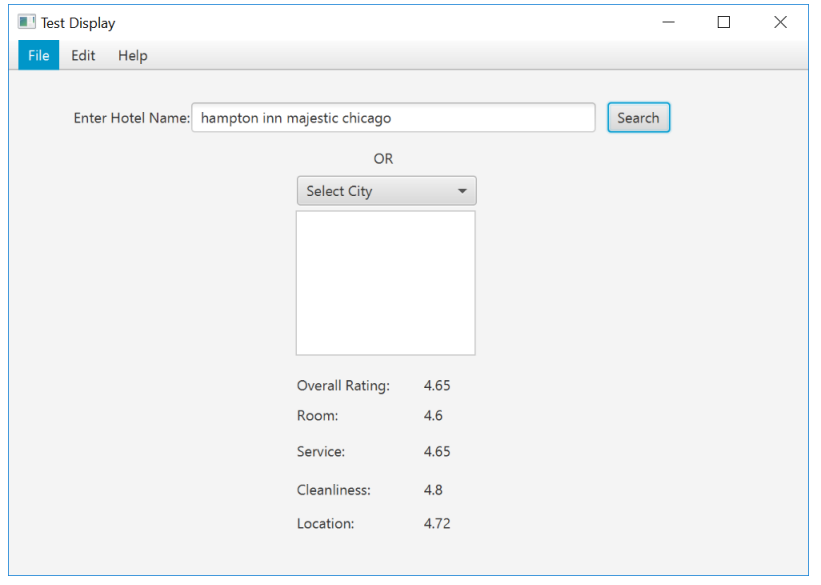

Fig. 6. Sample Query Interface Using Textbox

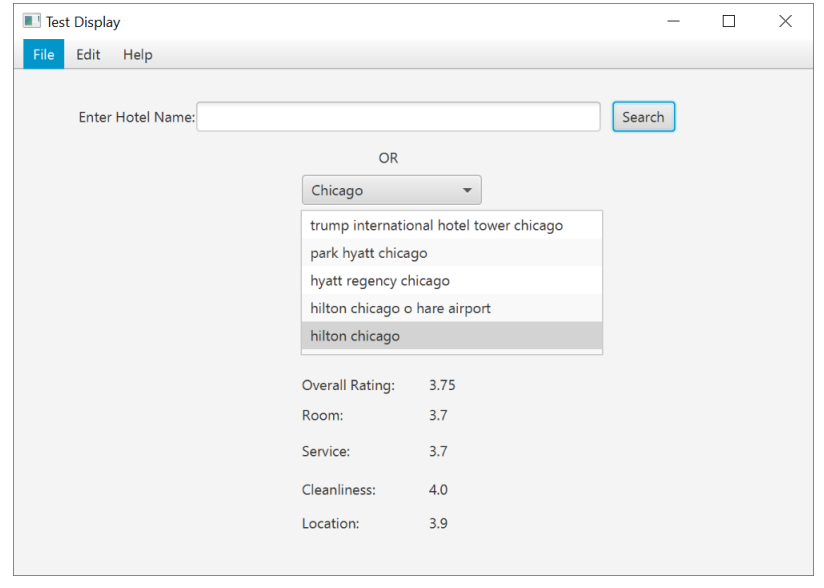

Fig. 7. Sample Query Interface Using List

5) Prototype Design: As a proof of concept, each student developed a working prototype for this hotel domain. Users can query about a specific hotel and the application displays the overall rating and average scores of individual features as shown in Figure 6. Alternatively, users could select a hotel from a list for a given city. It should display the overall rating of the hotel and the rating for other features, as shown in Figure 7. For a given city, users can also search by a specific search criterion, such as for the criterion "room score $>4$ and service score $>3.5$, and cleanliness score $>3.5$ and location score $>4$ " as shown in Figure 8. Students implement interface and application's interactivity using newly learned knowledge in CIT 44000 and knowledge from CIT 38800 and CIT 47900.

\section{RESULTS AND DisCUSSION}

To evaluate the newly designed CIT 44400 curriculum, instructional units were iteratively evaluated with various assessment items. We conducted Pre- and post-course survey to assess whether students' confidence level in applying knowledge from previous courses changed. Students performance data in the midterm examination from the Fall 2017 section were compared to the Fall 2018 section.

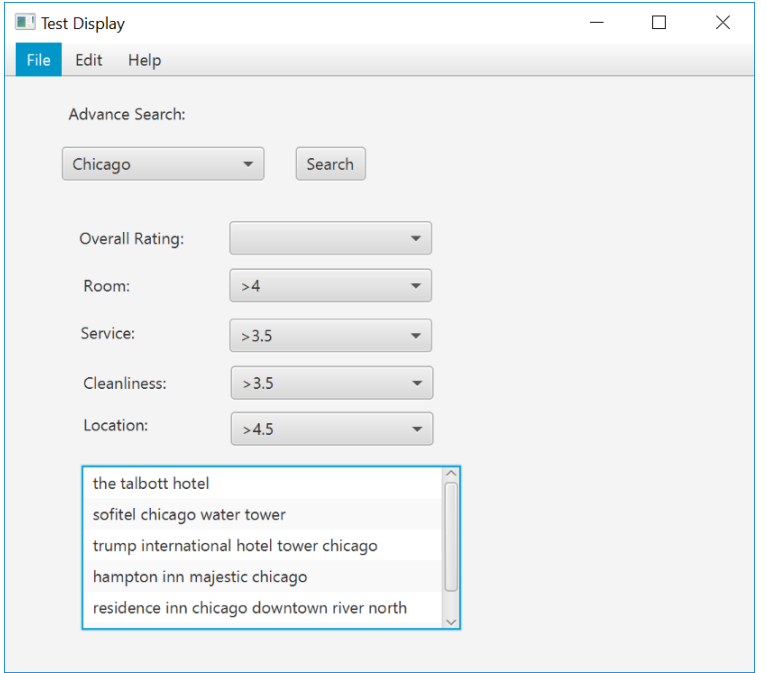

Fig. 8. Sample Query Interface for Complex Search

Students' performance data from the Fall 2018 sections were compared to the Fall 2017 sections. A total of 29 students' data was analyzed $(\mathrm{N}=15$ for Fall 2018; $\mathrm{N}=$ 14 for Fall 2017). Students typically take CIT 44400 in their junior or senior year. Most of our students were off campus residents, traditional-age, white students. However, there were few returning adult learners looking for a new career. In both semesters, approximately 55\% of participants were male students. Students' performance on the midterm examination in the new CIT 44400 course in Fall 2018 has improved by $12 \%$, compared to that of the old CIT 44400 in Fall 2017. In this experiment, the same tasks were used for both sections and all the tasks were evaluated using the same rubrics. We did not account for differences among students in our study; however, the student demographics of the courses from the Fall 2018 to Fall 2017 semesters are quite similar. There were no students in the Fall 2018 section who were repeating the course from the Fall 2017 semester, and the students in the Fall 2018 section would not have had more course preparation than those who took the course in the Fall 2017 section. The reason behind this improvement in Fall 2018 is that the new CIT 44400 course gave students a very comprehensive and hands-on learning experience that deepened their understanding. Students' project performance in the new CIT 44400 demonstrated that students successfully applied and integrated cross-course knowledge.

At the beginning and end of the course, we conducted surveys (see Appendix A) to assess whether students' confidence level in applying knowledge from previous courses changed. Pre- and post-course survey results show students' confidence level in how successfully they could integrate a database into an application at the end of the term increased. We also conducted midterm surveys (see Appendix B) to collect students' perspectives regarding their learning and crosscourse interaction. Mid-semester survey results showed $87 \%$ of students indicated that the project-based learning helped 


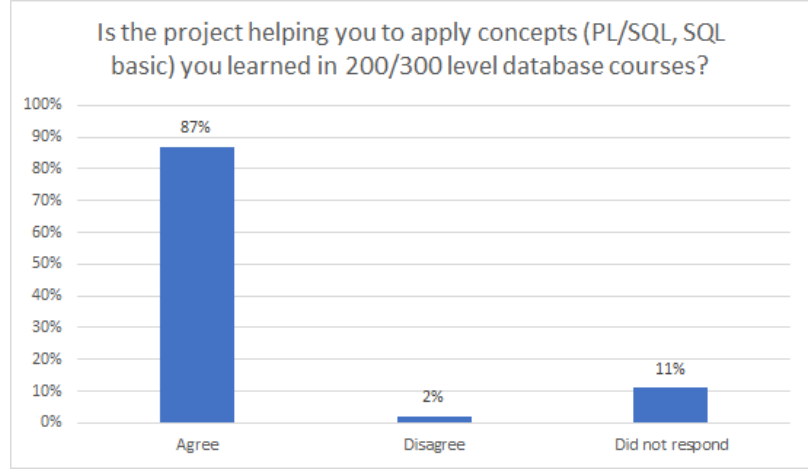

Fig. 9. Students' Perceptions Regarding Knowledge Integration

them apply concepts from lower-level courses. About $2 \%$ of students disagree with the knowledge integration and $11 \%$ students did not respond (shown in Figure 9). We analyzed the survey data and found that students who were not very happy or did not respond was because they did not have the required pre-requisite for the course or forgot lower-level course materials. A student's comment stated, "This course was definitely a struggle for me just because I didn't have all the course prerequisites." Mid-semester survey results also show $92 \%$ of students were happy with the course.

Course evaluation results show students are very "happy" with the "new" instructional methods and course resources. The rating on course evaluations for overall course satisfaction was 3.63 on a 4-point Likert scale. Students enjoyed their technology flexibility in the course. A student comment from the class stated that "This course gave us a lot of freedom to choose how we completed the project and what programming language we used. I really liked that part of the course." Students also enjoyed working through the whole project. Another student comment from the class stated that "This project $100 \%$ shows the full life cycle design of a real-life problem which is my favorite part about it." In addition to looking at course evaluations, a focus group was conducted in the Fall 2018 by a staff facilitator from the Center for Teaching and Learning from our institution and the report illustrated similar results.

We also received positive feedback from our industrial advisory board members on our curriculum modification. It gave us indications that we are moving in the right direction.

One key finding is prerequisites need to be defined properly. In Fall 2018, prerequisites for CIT 44400 were not defined correctly. In Fall 2018, CIT 21400 Introduction to data management was the only prerequisite for CIT 44400 . As a result, we had several students in the course who did not complete lower-level data management courses such as CIT 30400 Database Programming, and lacked knowledge they needed to apply in CIT 44400 project. That was a hurdle for the course. To overcome this obstacle, the instructor of the course provided a quick review on the required topics and assigned a small homework assignment. It allowed students to practice this knowledge in a low stakes homework assignment before applying in the project. Based on this experience, we included CIT 30400 database programming course and CIT 300-level programming course as the prerequisite for CIT 44400 course in addition to CIT 21400.

\section{CONClusion AND Future Work}

This curriculum enhancement helps students link and integrate knowledge gained through multiple courses and creates opportunity for students to apply cutting-edge technologies to real problems by working on projects. Students were so proud of the project that they thought they could list this course project in their portfolio.

With the success of this knowledge integration, one of our colleagues in our department is exploring knowledge interaction between two concentrations, namely web and data management. In our colleague's course, our web and data management students are working together. In this process, students from the web concentration need to communicate with students from the data management concentration to gather requirements and build solutions for them and vice versa. It is improving students' learning experience and social skills. It also simulates the real industry work environment.

Educators from other engineering and computing disciplines could also consider redesigning their curriculum to integrate cross-course interaction within a discipline or across disciplines by exploiting project-based learning. While designing the cross-course knowledge integration, educators need to ensure learning outcomes of lower-level and upper-level courses are aligned properly. Educators also need to provide a realworld problem and allow technology flexibility for application development to make the project-based learning a success.

\section{ACKNOWLEDGMENT}

This work was funded by Curriculum Enhancement Grant (CEG) 2018 received from Center for Teaching and Learning (CTL), IUPUI.

\section{REFERENCES}

[1] J. Wang and H. Chen, "Research and practice on the teaching reform of database course," in 2014 International Conference on Education Reform and Modern Management (ERMM-14). Atlantis Press, 2014.

[2] Y. Y. C. Fan and Q. Zhang, "Research on database education reform for applied talents," Information Engineering and Education Science, 2015.

[3] N. R. Council et al., Discipline-based education research: Understanding and improving learning in undergraduate science and engineering. National Academies Press, 2012.

[4] R. M. Capraro, M. M. Capraro, and J. R. Morgan, STEM projectbased learning: An integrated science, technology, engineering, and mathematics (STEM) approach. Springer Science \& Business Media, 2013.

[5] M. K. Smith, W. B. Wood, W. K. Adams, C. Wieman, J. K. Knight, N. Guild, and T. T. Su, "Why peer discussion improves student performance on in-class concept questions," Science, vol. 323, no. 5910, pp. 122-124, 2009.

[6] S. Bates and R. Galloway, "The inverted classroom in a large enrollment introductory physics course: a case study," in Proceedings of the HEA STEM learning and teaching conference, vol. 1, 2012.

[7] L. M. Stearns, J. Morgan, M. M. Capraro, and R. M. Capraro, "A teacher observation instrument for PBL classroom instruction." Journal of STEM Education: Innovations \& Research, vol. 13, no. 3, 2012.

[8] T. J. Moore and K. A. Smith, "Advancing the state of the art of STEM integration," Journal of STEM Education: Innovations and Research, vol. 15 , no. 1 , p. 5, 2014 
[9] A. Beckmann, "A conceptual framework for cross-curricular teaching," The Mathematics Enthusiast, vol. 6, no. 4, pp. 1-58, 2009.

[10] N. E. Selinski, C. Rasmussen, M. Wawro, and M. Zandieh, "A method for using adjacency matrices to analyze the connections students make within and between concepts: The case of linear algebra," Journal for Research in Mathematics Education, vol. 45, no. 5, pp. 550-583, 2014.

[11] M. M. Whiteacre and C. O. Malavé, "An integrated freshman engineering curriculum for pre-calculus students," in FIE'98. 28th Annual Frontiers in Education Conference. Moving from'TeacherCentered'to'Learner-Centered'Education. Conference Proceedings (Cat. No. 98CH36214), vol. 2. IEEE, 1998, pp. 820-823.

[12] D. Laboy-Rush, "Integrated STEM education through project-based learning," Boston, MA: Learning. com, 2011.

[13] J. C. Nwokeji and P. S. T. Frezza, "Cross-course project-based learning in requirements engineering: An eight-year retrospective," in 2017 IEEE Frontiers in Education Conference (FIE). IEEE, 2017, pp. 1-9.

[14] L. Debs and M. Zimpfer, "Developing and applying an undergraduate cross-course team assignment," in 2018 IEEE Frontiers in Education Conference (FIE). IEEE, 2018, pp. 1-5.

[15] D. Cogean, M. Fotache, and V. Greavu, "NoSQL in higher education. a case study," in Proceedings of the IE 2013 International Conference, Bucuresti, 2013.

[16] K. Ganesan, "Opinrank review dataset," 2010.

\section{APPENDIX}

\section{A. Beginning and End of the Term Survey}

Your professor cares about your experience in learning of database in CIT 44400 and wants to know if your learning needs were met. Obtaining your input is imperative when attempting to understand what did or did not work in your learning database. Your input will help your professor to improve CIT 44400 in future. Based on your experience so far in CIT 21400, 30400, 27000, or 38800 please answer each of the questions below.

Question 1: Please select the courses you have already taken at IUPUI?

- CIT 30400

- CIT 27000

- CIT 38800

Question 2: Do you know how to import data into database from external sources?

- Yes

- No

Question 2: Given a project specification what is your confidence level to work with the full life cycle of the project (requirements analysis, design, implementation, and testing)

- Mostly non-confident

- Not confident

- Confident

- Mostly confident

- Very confident

Question 3: Based on your experience in CIT 21400, 30400, 27000 or 38800 what is your confidence level to integrate database in an application.

- Mostly non-confident

- Not confident

- Confident

- Mostly confident

- Very confident

\section{B. Midterm Survey}

Question 1: At this point in the semester, what are the most successful aspects of the CIT 44400 project for you? Explain why.

Queation 2: At this point in the semester, what are the least successful aspects of the CIT 44400 project for you? Explain why.

Queation 3: Based on your experience in CIT 44400 project, is the project helping you to apply concepts (PL/SQL, SQL basic) you learned in 200/300 level database courses? Explain your answer with some examples.

Queation 4: Based on your experience in CIT 44400 project, how is the project helping you learning how to integrate database with an application by importing data from an external source?

Queation 5: Based on your experience in CIT 44400 project, how is the project assisting you to explore full life cycle design of a real-life problem?

If you could design CIT 44400 project (change or add aspects), what would you do? 